\title{
Strategies in conservative dentistry against dental avulsion: protocol proposal for decision making
}

\begin{abstract}
Dental traumatisms have a high prevalence in any population, being the second cause of dental care after caries. They constitute a dental emergency because the time elapsed until the treatment marks the prognosis of the tooth. Of all of them the most serious and complex, is the dental avulsion in which the tooth is completely dislodged from the alveolus and must be reimplanted immediately if it is a permanent tooth. It is important that both the children and their caregivers know how to act in the face of an emergency of this nature, and that the dentist himself is clear that the cascade of decision-making must be present in the face of each clinical situation.
\end{abstract}

Keywords: tooth avulsion, traumatic tooth injure, tooth prognosis, dent reposition, dental reimplant, storage media, dental traumatology guidelines
Volume 7 Issue I - 2020

\author{
Marcos Moradas Estrada \\ Assistant Professor, University of Oviedo, Spain
}

Correspondence: Marcos Moradas Estrada,Assistant Professor, University of Oviedo, Spain, Email marcosmord@gmail.com

Received: May 23, 2019 | Published: January 23, 2020

\section{Introduction}

Alveolar tooth injuries are those that occur with dental and paradental lesions in which the tooth may suffer alterations of its integrity as well as may be partially or totally displaced from its habitual position. These alter the function and aesthetics, being able to repercutir psychologically in the individual. They are considered as an emergency and should be dealt with immediately and in a resolutive manner. They represent a public health problem, especially among children and adolescents, with figures ranging from $4.2 \%$ $3.6 \%$, thus becoming the second cause of dental care after caries. The maximum incidence occurs around 10 years, with predominance in males, although the differences between sexes are becoming smaller due to the increasing presence of women in sports life and in any other contact activity. Among the most frequent causes are falls, often 'sudden', which are enhanced in younger children due to the onset of ambulation and lack of coordination, followed by sports injuries, especially in those considered as contact. Among these, the sports that present a higher percentage of dental injuries are baseball, basketball and then football. Despite what one might believe other more aggressive sports such as boxing or ice hockey prevalence is lower due to mandatory use of mouth guards. In this data highlights the importance of the use of mouth guards as a more effective preventive measure. However, these are not the only causes, traffic accidents, fights or traumas of pathological origin are also the cause of alveolital trauma. On the other hand, there is a cause to be taken into account due to the implications that it entails, as is the case of the abused child. Between $50 \%$ and $70 \%$ of these children present lesions on the face, mouth and sometimes neck, being the responsibility of the dentist their observation and diagnosis and immediately their communication to the relevant authority. ${ }^{1-5}$

In addition to the direct causes, there are certain factors that increase the risk of these traumatisms, such as lip incompetence, raised prominence, alcohol and drug consumption, along with anatomical and occlusal alterations, such as a class II malocclusion or the habit of Mouth suction, digital suction etc. The most frequently affected tooth is the upper central incisor, followed the upper side and the lower incisors. In permanent teeth, the predominant injuries are non-complicated crown fractures, while in temporaries; the tooth is more frequent than luxation or avulsions rather than fractures. This difference is due to the fact that in the preschool child the alveolar processes have wider spinal spaces and a more flexible periodontal ligament. In cases of dental avulsion, at any age, genus or dentition, the most serious and most complex type of lesion. ${ }^{6,7}$

\section{Material and method}

A descriptive bibliographical review of the evidence provided in indexed articles and other bibliographic sources, such as books, theses and especially to understand that it is a pathology difficult to treat and involving different professionals, contributions by Committees of experts, scientific societies or conclusions of national and international congresses. It was performed using the main search engines like Medline, Crochaneu, obtaining a total of 355 results. These were analyzed and after checking whether or not they met the inclusion/ exclusion criteria of this study, as referred to the definitive dentition, protocol of action, date of publication, index of impact of the journal or percentile of publication were finally 23 articles of Bibliographic review, published in a fork that goes from 2007 to $2015 .^{8-10}$

\section{Discussion}

\section{Concept of avulsion}

The avulsion or extraarticulation consists of the complete displacement of the tooth outside the alveolus, causing the rupture of the periodontal ligament and the vascular-nervous package with the consequent necrosis of the pulp. All this can be accompanied by a fracture in the alveolar spindle. Avulsions account for between $1 \%$ $16 \%$ of all permanent tooth traumas and $7-13 \%$ of temporary teeth. ${ }^{11,12}$ Although they are not the most frequent, they are the most urgent, 
since the time between the accident and the treatment will mark the prognosis of the tooth. In most cases, the avulsions are isolated lesions and occur in a single tooth, mainly in maxillary central incisors. To a lesser extent avulsion of 2 or 3 teeth, or even an entire anterior sector, could occur. ${ }^{13,14}$

\section{Guidelines for the action of the accident}

If it is a temporary tooth, it should never be reimplanted because it can affect the development of the permanent germ, due to the proximity between the root apex of the temporary tooth and the permanent germ. Complications that may arise include dental malformations and eruptive problems such as impaction. However, if it is a permanent tooth, it is best to reimplant it immediately after the accident has occurred, before the cell viability of the periodontium is lost. Some studies claim that necrosis of the cells of the periodontal ligament occurs after 60 minutes of avulsion; others argue that they cannot survive more than 18 minutes in a dry environment, dying in half at 30 minutes and most at 120 Minutes. ${ }^{15-20}$ The death of these cells generates complications such as ankylosis and external resorption of the root, which in turn can cause the arrest of maxillary or mandibular growth at that point. If the tooth is dirty it can be washed with water or saline before reimplanting, but it can never be brushed. If the tooth is reimplanted it is favorable for the patient to hold it in position by biting a tissue or similar object until receiving appropriate dental treatment. This maneuver will quantitatively and qualitatively reduce the bleeding of the alveolus and will help the tooth receive vascular supply.

\section{Means of transport}

Most teeth are not reimplanted within the time frame favorable for the survival of the periodontal ligament. If the parent or caretaker of the child is not able to reimplant it, the tooth must be immersed immediately in a medium capable of maintaining cellular viability. This medium should have a $\mathrm{pH}$ compatible with cell life, antioxidant capacity, minimal or no microbial contamination and should be accessible to the population. According to the American Society of Endodontics, Hank's balanced salt solution (HBSS) is a standard culture medium used in biomedical research for cell preservation. Immersion of the avulsed tooth has been shown to prevent root resorption by $91 \%$. Hank's balanced solution can maintain the vitality of the fibroblasts for $24 \mathrm{~h}$, which could allow the immediate treatment of lesions more severe injuries during the trauma. There are also other media with similar or even greater effectiveness than Hank's solution such as Viaspam, used for organ transport. But these are not commercialized for the public. It should be borne in mind that these are means with high cost and little accessibility for the population, and that the most common and accessible means the best is milk, pasteurized and cold, which is able to maintain the vitality of the periodontal ligament for 2-3 hours. Milk is an adequate means of transport because it is an isotonic solution with a suitable $\mathrm{pH}$ and osmolarity, a null or low bacterial load and also presents growth factors and nutrients. Other less efficient means of transport would be physiological saline or saliva, which maintains vitality for 1-2 hours, while water would not represent a good means of transport. No matter how long each medium is effective, the best prognosis is obtained when the tooth is reimplanted for 30 minutes after injury. Should you reimplant it within 30 minutes of injury? In case the implant is not possible, the means of transport should be renewed every 60 minutes. ${ }^{21}$

\section{Clinical treatment}

If, when the patient arrives at the consultation, the tooth has already been reimplanted, it is not extracted again. The area is cleaned with saline solution or chlorhexidine and is ferulized having previously verified by radiographs that the tooth occupies a correct position within the alveolus. Usually a flexible or semi-rigid splint is used for 7-10 days although, after this time the tooth continues to have mobility becomes acceptable. As treatments, systemic antibiotics are prescribed for a week, such as doxycycline or penicillin, and the following recommendations are established for the patient: to consult the doctor to consult the need for tetanus vaccine, a soft diet for two weeks and rinses with saline or chlorhexidine at $0.12 \%$ Twice a day for a week. If the tooth has not been reimplanted immediately, the first thing to do in the consultation is to place it in the best preservation medium while the scan is performed. It is recommended to introduce it into one of the aforementioned solutions, such as Hank's for 30 minutes or more, so that the fibroblasts recover the lost metabolites. Clinically the empty socket is seen without the tooth which could be housed in the adjacent soft tissues. Another possible option is that the tooth actually has not suffered an avulsion if not an intrusion and is housed in the socket. If you do not find the tooth at the scene of the injury, an $\mathrm{x}$-ray should be done to rule out this possibility. ${ }^{22,23}$

When the tooth is already present the apex closed and has remained outside the socket less than an hour must be reimplanted as fast as possible. It is necessary to have cleaned the surface of the tooth with saline solution or Hank's solution and to have prepared the alveolar bed, which consists of removing the clot with saline serum and replacing the alveolar wall, if it was fractured, with a blunt instrument. If the tooth had the open apex in addition to all of the above, it should be immersed in a solution of doxycycline $(1 \mathrm{mg}$ every $10 \mathrm{ml}$ of saline solution) to promote revascularization. But if the elapsed time is longer than the time then the cells of the periodontal ligament will have died and what is sought is to prepare the tooth to resist, as far as possible, the resorption by bone substitution, for which it is immersed in fluoride $2 \%$ tin or sodium fluoride for 5 minutes. The controversy comes when the tooth in addition to remaining outside the alveolus more than 60 minutes has the apex open, as it is the situation with worse prognosis. Some authors recommend not reimplanting, arguing the failure of the same by their future infraocclusal position, while others recommend reimplanting it later to have the treatment of ducts out of the mouth and to preserve it later in the arcade until its replacement by another therapeutic option such as implant. ${ }^{24,25}$

After one or two weeks, the flexible splint would be removed and endodontic treatment would begin on the teeth with a closed apex. In those with an open apex the vascularization would be controlled and in case of not occurring, a process of apicoformación would be carried out with calcium hydroxide or MTA. In any case of 2-3 weeks, 3-4 weeks, 6-8 weeks, one year and annually for 5 years, clinical and radiographic examinations must be performed.

\section{Forecast}

The immediate attention of a tooth that has been traumatized and even more so when it comes to avulsion is crucial for long-term success. The prognosis will depend on the viability of the remnant cells of the periodontal ligament, the conditions of the cementum root and the bacterial contamination. All these factors vary according to the time the tooth remains in the oral medium, as well as the measures 
taken during that time and the conservation medium in which it is housed. Therefore, a short extra oral period, good endodontic therapy, administration of antibiotics by systemic route and correct treatment of the tooth are factors that lead us to reach a good prognosis with a frank good chances of surviving that can even reach Data ranging from $60 \%$ in the medium term to $40-70 \%$ in the long term (more than $8-10$ years). However, the reality is that complications such as ankylosis, excessive mobility or reabsorption are common, reaching values between $57 \%$ $-80 \%$, and most of the reimplanted teeth are lost within 5 to 7 years. According to the International Association of Dental Traumatology and the American Endodontic Association only 4 to $50 \%$ of avulsed teeth survive more than ten years. Therefore, the true dental challenge is not the reimplantation itself, but the maintenance of the tooth in the arch over time. What happens when a tooth is reimplanted is that a clot immediately forms in the area of the periodontal ligament that will be replaced two weeks later by collagen fibers as a healing. Once this occurs, reabsorption phenomena start along the root surface that can evolve to a superficial resorption with repair and new cement or to an inflammatory reabsorption or ankylosis. ${ }^{26}$

In summary, the prognosis can be defined and specified according to the type of repair that takes place in the space of the periodontal ligament. According to the studies of Andreasen we distinguish four groups: the group $\mathrm{A}$, considers as success that a complete regeneration of the periodontal ligament occurs; Group B, considers as acceptable that areas of superficial root resorption occur which are repaired with cement; Groups C and D constitute the failure and present with ankylosis and inflammatory root resorption respectively. ${ }^{27}$

\section{Social education}

If the time and measures taken immediately after the injury are critical to the prognosis of the tooth, it is therefore essential that people know how to act. Most children as well as parents, teachers or coaches do not know what to do in the event of trauma. Most often the broken tooth fragment or the avulsed tooth is not even recovered. A study of 256 tutors and 92 children at the Pediatric Dental Clinic of Niigata University Dental Hospital revealed that $75 \%$ of the respondents did not know that an avulsed tooth could be reimplanted and less than $20 \%$ knew that the best medium to conserve it was milk. Among the group of people who had received information on how to act, $45 \%$ had obtained it from television programs and only $10 \%$ from the dentist. Another study, carried out among 100 families and persons in charge of the children who come to the department of the National Autonomous University of Mexico, found that $87 \%$ of the respondents never received information about how to act before a trauma, as only $49 \%$ Showed interest in recovering a tooth that has been avulsed and only $18 \%$ would handle that situation correctly. Therefore, it is very important to encourage educational campaigns for the population, as well as to instruct those responsible for the management of children in places at risk of injuries, see colleges, sports centers, kindergartens, etc. $^{28,29}$

\section{Conclusion}

Dental trauma is a dental emergency of high prevalence and difficult to solve, more when you are not trained or have a schematic of actions, materials and techniques necessary and play with the times. Temporary teeth should never be re-implanted, while permanent teeth should be replaced immediately and if not possible, they should be preserved in a suitable medium for the survival of periodontal ligament cells, with Hank's balanced saline solution being the best
Conservation method. Although cold milk is more accessible, simple and economical as a standard method of preservation. The prognosis of reimplanted teeth depends on extraoral time and measures taken during this time, and is doubtful in the long term.

\section{Acknowledgments}

None.

\section{Funding}

None.

\section{Conflicts of interest}

Author declares that there is no conflict of interest.

\section{References}

1. Andersson L, Andreasen JO, Day P, et al. International Association of Dental Traumatology guidelines for the management of traumatic dental injuries: 2. Avulsion of permanent teeth. Dent Traumatol. 2012;28(2):88-96.

2. Petrovic B, Marković D, Peric T, et al. Factors related to treatment and outcomes of avulsed teeth. Dent Traumatol. 2010;26(1):52-59.

3. Trope M. Avulsion of permanent teeth: theory to practice. Dent Traumatol. 2011;27(4):281-294.

4. Pfadt E, Carlson DS. Avulsión dental. Nursing. 2012;30(10):7.

5. García MI, Palma J, Espinozaii E. Treatment of an avulsed teeth: case report, 5 years follow-up. Rev Odont Mex. 2010;14(4):249-257.

6. Lee JY, Divaris K. Hidden consequences of dental trauma: the social and psychological effects. Pediatr Dent. 2009;31(2):96-101.

7. Schildknecht S, Krastl G, Kühl S, et al. Dental injury and its prevention in Swiss rugby. Dent Traumatol. 2012;28(6):465-469.

8. Andreasen JO, Randskov T, Ssac V. Predictors for healing complications in the permanent dentition after dental trauma. Endod Top. 2008;14(1):20 27.

9. Diangelis AJ, Andreasen JO, Ebeleseder KA, et al. International Association of Dental Traumatology guidelines for the management of traumatic dental injuries: 1. Fractures and luxations of permanent teeth. Dent Traumatol. 2012;28(1):2-12.

10. Malmgren B, Andreasen JO, Flores MT, et al. International Association of Dental Traumatology guidelines for the management of traumatic dental injuries: 3 injuries in the primary dentition. Dent Taumatology. 2012;28(3):174-182.

11. Gunepin M, Zadik Y, Derache F, et al. Nonbarotraumatic tooth fracture during scuba diving. Aviat Sp Env Med. 2013;84(6):630-642.

12. Pujita $\mathrm{C}$, Nuvvula $\mathrm{S}$, Shilpa $\mathrm{G}$, et al. Informative promotional outcome on school teachers ${ }^{\text {ee }}$ knowledge about emergency management of dental trauma. J Conserv Dent. 2013;16(1):21-27.

13. Arikan V, Sönmez H. Knowledge level of primary school teachers regarding traumatic dental injuries and their emergency management before and after receiving an informative leaflet. Dent Traumatol. 2012;28(2):101-107.

14. Levin L, Zadik Y. Education on and prevention of dental trauma: it"es time to act! Dent Traumatol. 2012;28(1):49-54.

15. Levin L, Jeffet U, Zadik Y. The effect of short dental trauma lecture on knowledge of high-risk population: an intervention study of 336 young adults. Dent Traumatol. 2010;26(1):86-89. 
16. Flores MT, Andreasen JO, Bakland LK, et al. Guidelines for the evaluation and management of traumatic dental injuries. Dent Traumatol. 2001;17(5):193-198.

17. Guidelines for the Evaluation and Management of Traumatic Dental Injuries. International Association of Dental Traumatology. 2011.

18. Flores MT. Información para el Público, Pacientes y Servicios de Emergencias sobre Lesiones Dentales Traumáticas. In: Andreasen JO, Andreasen FM, Andersson L, editor. Texto y Atlas a Color de Lesiones Traumáticas a las Estructuras Dentales. $4^{\circ}$ ed. Caracas: Amolca; 2010. p. $869-875$.

19. Recommended Guidelines of the AAE for the Treatment of Traumatic Dental Injuries. American Association of Endodontists. 2013.

20. Save your tooth posters. International Association of Dental Traumatology. 2011

21. Raoof M, Zaherara F, Shokouhinejad N, et al. Elementary school staff knowledge and attitude with regard to first-aid management of dental trauma in Iran: a basic premise for developing future intervention. Dent Traumatol. 2012;28(6):441-447.

22. Andersson L. New guidelines for treatment of avulsed permanent teeth Dent Traumatol. 2012;28(2):87.
23. Fleming PS, Koletsi D, O'Brien $\mathrm{K}$, et al. Are dental researchers asking patient-important questions? A scoping review. J Dent. 2016;49:9-13.

24. Feldens CA, Borges TS, Vargas-Ferreira F, et al. Risk factors for traumatic dental injuries in the primary dentition: concepts, interpretation, and evidence. Dent Traumatol. 2016;32(6):429-437.

25. Tseveenjav B, Furuholm J, Mulic A, et al. Survival of extensive restorations in primary molars: 15-year practice-based study. Int $J$ Paediatr Dent. 2018;28(2):249-256.

26. Koletsi D, Fleming PS, Eliades T, et al. The evidence from systematic reviews and meta-analyses published in orthodontic literature. Where do we stand? Eur J Orthod. 2015;37(6):603-609.

27. Turner L, Shamseer L, Altman DG, et al. Consolidated standards of reporting trials (CONSORT) and the completeness of reporting of randomised controlled trials (RCTs) published in medical journals. Cochrane Database Syst Rev. 2012;11:MR000030.

28. K Khan, PO'Donovan. The CROWN Initiative: journal editors invite researchers to develop core outcomes in women's health BMC Womens Health. 2014;14:75

29. Bala MM, Akl EA, Sun X, et al. Randomized trials published in higher vs. lower impact journals differ in design, conduct, and analysis. J Clin Epidemiol. 2013;66(3):286-295. 